\title{
The Inheritance and Innovation of Quanzhou Jincang Embroidery Art in Modern Bag Design
}

\author{
Mengdi Sun ${ }^{1, *}$ Youjun Tong ${ }^{2}$
}

\author{
${ }^{1}$ Xiamen Academy of Arts and Design, Fuzhou University, Xiamen, Fujian, China \\ ${ }^{2}$ Jinjiang Fuzhou University Science Park Committee, Jinjiang, Fujian, China \\ *Corresponding author. Email: 745980989@qq.com
}

\begin{abstract}
Jincang Embroidery, as a traditional embroidery craft with regional characteristics of Quanzhou, enjoys rich historical culture. With the loss of the ecological environment of the traditional craft of Jincang Embroidery, the death of the older generation of Jincang Embroidery artists, as well as the impact of machine embroidery, the traditional craft of Jincang Embroidery is facing the dilemma of no successor. In the paper, the techniques, color application and decorative pattern characteristics of Jincang Embroidery are analyzed. Besides, its innovative application in modern popular bag design is displayed. By combing the ancient art of Jincang Embroidery with modern fashionable bag design, a new way of inheritance is endowed to it.
\end{abstract}

Keywords: Jincang Embroidery, bag, innovative design

\section{INTRODUCTION}

As for the origin of the name "Jincang Embroidery", the embroidery thread wrapped in gold foil looks like the shape of green onion, and it is called Jincong Embroidery among people. "Cong" and "Cang" sound similarly in Quanzhou dialect, so it was called "Jincang Embroidery" later. Embroidery has been always dominant in the development history of China. During the Song and Yuan Dynasties, Citong Embroidery in Quanzhou was quite famous. And originally tiny workshops gradually developed into large-sized embroidery factories. After the royal family moved to Quanzhou during Southern Song Dynasty, Quanzhou embroidery industry gained rapid development, and Quanzhou Citong Embroidery was widely used in the royal apparel. Since then, the strong religious culture and local opera in Quanzhou also promoted the further development of Quanzhou embroidery, which began to be applied in opera costumes and religious embroidery products. At present, Quanzhou Jincang Embroidery, as the inheritance of Citong Embroidery, has lost the previous prosperity.

Quanzhou Jincang Embroidery was listed as the National Intangible Cultural Heritage in 2009, which attracted social attention and promoted its development to some degree. However, there are still two serious problems. First of all, there is so serious lack of craft personnel that Quanzhou Jincang Embroidery may not be inherited. Due to low efficiency, low income, much time consumption, and machine replacement, few young people are willing to learn the traditional Jincang
Embroidery. In addition, with the death of the older craftsmen, there is a very serious situation for the inheritance of Quanzhou Jincang Embroidery. Secondly, the craftsmen of Quanzhou Jincang Embroidery lack of creative consciousness, and only apply it in limited scopes. Up to now, its carriers are still dominated by religious embroidery, such as dragon python tablecloth, Zhentou, temple items, as well as local opera, and cloth puppet show clothing. It is difficult to attract the young consumer groups in the modern society. Therefore, certain innovation is quite necessary for it. In the authors' opinion, while keeping its religious application, Jincang Embroidery can be applied in modern clothing and daily necessities as design factors, expending its range of application.

\section{ARTISTIC FEATURES OF QUANZHOU JINCANG EMBROIDERY}

\section{A. Quanzhou Jincang Embroidery involves very complicated craft and unique technique}

It is also spiral double-gold embroidery forms various patterns with thicker spiral embroidery threads, and fixes on the bottom of the embroidery with red threads. The traditional Quanzhou Jincang Embroidery threads are wrapped with gold foil. Gold color is bright and lively, so the patterns of embroidery are naturally more gorgeous. Quanzhou Jincang Embroidery involves more unique techniques than traditional Chinese embroidery. Its technique is divided into flat spiral double-gold embroidery and raised spiral doublegold embroidery. The former makes threads compact 
and spiral, and fixes with red threads every other half a centimeter. The red threads are evenly arranged in the hands of the old artists, so that whole design can present delicate and beautiful outline. By comparison, the latter presents strong visual effect, forms a strong sense of space through the form of consolidation, overlap and accumulation, and creates a threedimensional effect. The most basic embroidery method is to attach a cloth to sew on original embroider bottom, put aside certain space between cloth and raw material to fill cotton, make sure embroidery pattern sample upright, and then spirally use gold threads in convex position of cotton mat. Besides, the commonly-used crafts of the raised spiral double-gold embroidery also include Lizhitiao, Longlindiejia, and Boluotu [1]. For example, Lizhitiao is a complicated and unique technique. The step is to first arrange thicker cotton line inside the pattern, fix with embroidered line across two cotton threads, interlace up and down, and form the texture effect of litchi skin [2]. The raised spiral doublegold embroidery is the core and soul of Quanzhou Jincang Embroidery. It is mostly applied in important parts of patterns, such as animal head and dragon head to change the previous traditional plane embroidery effect and make embroidery products more exquisite and gorgeous with the combination of embroidery threads wrapped by gold foil.

\section{INNOVATIVE APPLICATION OF QUANZHOU JINCANG EMBROIDERY COLOR ELEMENT IN MODERN BAG DESIGN}

Quanzhou Jincang Embroidery products are full of the unique regional characteristics of southern Fujian. Most of the embroidery products take red satin as the embroidery base, and are attached with gold, yellow, green, black embroidery threads, forming strong and obvious color contrast. Inevitably, the selection and application of the colors are closely related to the local culture of Quanzhou. Various factors such as ancient house with red brick and red tile in Quanzhou, magnificent religious buildings, red and black local traditional clothing influence local people's aesthetic psychology of color, who thus have a special preference for red, gold and black. Dragon python tablecloth is a case in point to show the artistic characteristics of Quanzhou Jincang Embroidery. The so-called goldembroidered tablecloth has a long history. According to the legend, Wu Zetian asked court eunuch to order a tablecloth to cover her bare legs and feet under the table. Finally, a tablecloth with Jincang Embroidery was adopted. Afterwards, such practice was popular among common people. Until today every local household in Quanzhou must a tablecloth, especially the one with patterns of dragon and python. Red embroidery bottom is the necessary of tablecloth, and the red that represents China is more popular. The red embroidery bottom is matched with large area of gold. The dominant colors of red and gold have very high purity and lightness, creating rich and luxuriant sense of vision. Moreover, the auxiliary colors of tablecloth mainly include complementary color system such as green, blue and purple. Their lightness of auxiliary colors is reduced to highlight the dominant colors. The striking contrast in color system can make patterns more bright-colored, and also avoid multi-colors from causing the mixed and disorderly integral vision.

More research and practice are required to innovatively apply the color elements of Quanzhou Jincang Embroidery products in modern bag design, and ensure they are popular among consumers. In the opinion of the authors, if the dominant colors red and gold of Quanzhou Jincang Embroidery are directly copied in the design of modern bags, they tend to make the bags exaggerative and cheap, and it is difficult to attract consumers ("Fig. 1"). Morandi color system, and fresh quietly elegant gray tone with low saturation are more popular in modern society because they are of a natural sense of high grade. Therefore, the authors try to reduce the saturation of the dominant colors of red and gold and supplement colors in Quanzhou Jincang Embroidery, matching black and white perfectly. The color-less system can effectively reduce the exaggerative effect brought by red and gold. Furthermore, the complementary color collocation of Quanzhou Jincang Embroidery can be referred to in the design of modern bags. High purity and sharp contrast of colors can make products create a relaxed and lively visual psychology, being more in line with the consumption needs of young people.

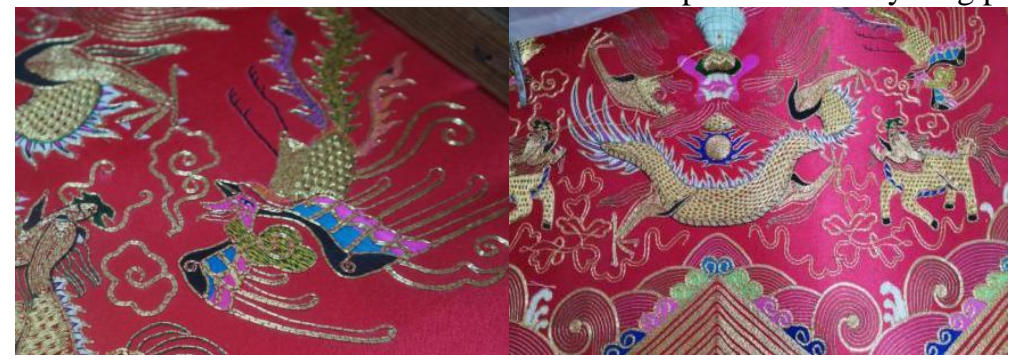

Fig. 1. Part of dragon python tablecloth. 


\section{INHERITANCE OF JINCANG EMBROIDERY TECHNOLOGY COMBINING WITH MODERN AESTHETIC}

Embroidery craft has been extensively applied in dress in ancient times. According to the record of Book of Documents, court costume system stipulated "embroidery on clothes" as early as 4000 years ago [3]. With the continuous development of the society, more and more new crafts, new technology appear, and then complicated manual embroidery gradually withdraws from the historical stage. As people's cultural awareness has been increasing in recent years, China has begun to attach importance to traditional culture. Increasing number of designers in the clothing industry alone have returned to embroidery, the traditional Chinese handicraft. Nowadays, the embroidery technology has been commonly applied in modern clothing designs, such as cheongsam and wedding dress, but it is rarely applied in costume design. Bag category is one of the most popular clothing accessories at present. The innovative combination of materials, techniques and decorative patterns with the traditional craft Jincang Embroidery will certainly bring something new and refreshing, and promote the inheritance and development of Jincang Embroidery.

\section{A. Combination of different materials with traditional technology}

Ancient women regard embroidery as adornment, created delicate design grain patterns in bag, sachets, package and other accessories, and then sent them as gift to family members or friends, and also expressed their affection. Human being mastered textile technology earlier, so the original embroidery technology is also used in the fabric material. In the modern bag design, the cloth surface materials are dominated by casual style of canvas bags, backpacks and so on. Quanzhou Jincang Embroidery can be combined with modern leisure cloth surface bags. On the one hand, the material is similar to its original faille, which will not make people feel abrupt and tend to be accepted. On the other hand, casual style of bags are the popular product of modern society exactly, and are deeply loved by young people, so they can be quickly propagandized in young group. In the practice cases of Jincang Embroidery bag design scheme I ("Fig. 2") and scheme II ("Fig. 3"), the patterns of Jincang Embroidery technology is applied to the more conventional canvas bag belt, which is innovative and presents a good visual effect. In the development history of luggage and bags in China, most of the bags are of regular shape, and are made of wood and cloth. And there are fewer leather bags. Under the continuous influence of western culture, leather bags gradually appear. Leather bags are quite popular among people in the design of modern bags. For example, the most popular classic bags of international famous brands LV, FENDI and HERMES are often is curvaceous handwork leather bags. Top-class leather bags are mostly handcrafted. It usually takes dozens of days to complete one such bag. Rather than a tool to hold items, such bag is a piece of artwork in the eye of some people. It is also very consistent with the concept of Jincang Embroidery. In modern society, leather bags often present a kind of solemn and elegant psychology feeling. To combine Jincang Embroidery with it, some details need to be considered in the design of patterns. At the same time, the combination of embroidery with leather can greatly increase the three-dimensional effect of the leather surface, which integrates fashion and tradition.

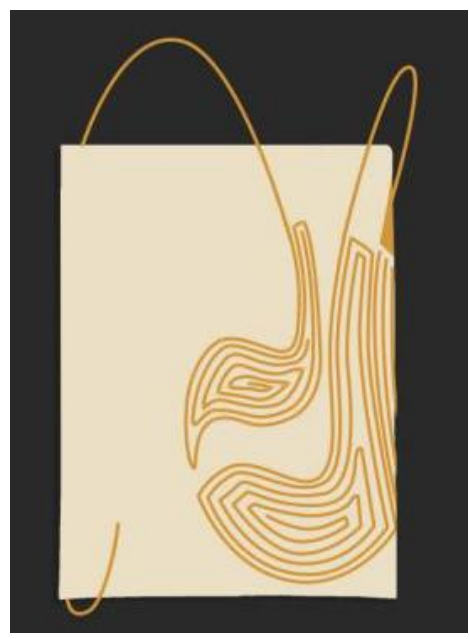

Fig. 2. Jincang Embroidery bag design scheme I

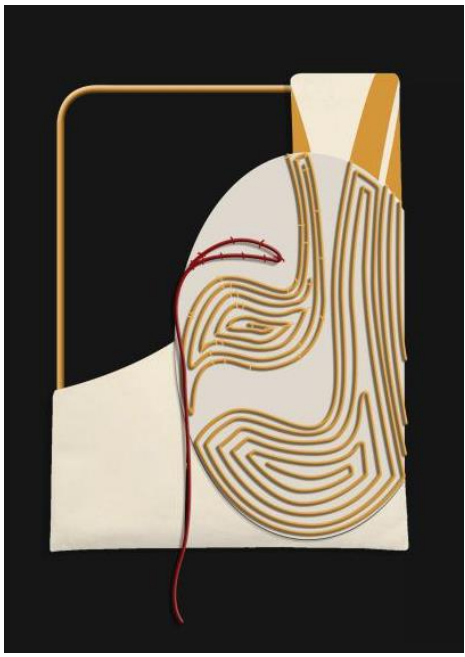

Fig. 3. Jincang Embroidery bag design scheme II. 


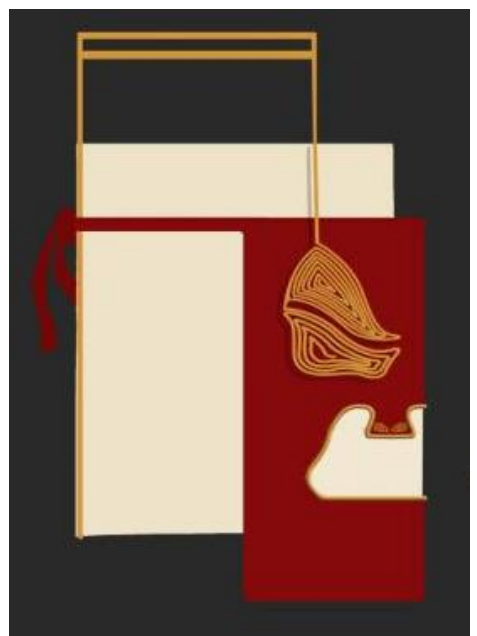

Fig. 4. Jincang Embroidery bag design scheme III.

\section{B. Combination of spiral double-gold embroidery technology with modeling}

The spiral double-gold embroidery technology of Quanzhou Jincang Embroidery is the most amazing, and it is a good creative starting point for the designs of modern bags. If the traditional material of soft gold thread is replaced with the most commonly-used aluminum threads in modern clothing design, it is convenient for modeling and has a certain stiffness effect. Besides, if the gold thread is replaced with aluminum wire to make decorative patterns on the bag, the hard aluminum wire will not be confined to the surface of bag fabric, can be combined with bag modeling, such as directly make the bag handle and decorative patterns. For example, in the practice case of scheme III ("Fig. 4"), aluminum wire is first used to create decorative patterns in the front, and create the shape of handle in the upper part. The combination of traditional techniques and new materials not only conforms to modern aesthetic, but also realizes the innovative application of Jincang Embroidery, and effectively shows the elements of Chinese traditional culture. With the development of modern science and technology, new technologies and new processes such as $3 \mathrm{D}$ printing technology will emerge constantly. For instance, the spiral double-gold embroidery technology of Quanzhou Jincang Embroidery can be combined with 3D printing technology for technological innovation.

\section{Recreation of traditional pattern elements combining modern aesthetics with different artistic expressions}

Jincang Embroidery is extensively used in religious articles, and the decorative patterns are mostly ancient totem, religious patterns such as dragon and phoenix, eight auspicious patterns. etc. In the modern society with advanced information, science and technology, however, if designers of modern bags completely and blindly copy religious embroidery patterns of Jincang Embroidery, they cannot attract consumers in the modern market, especially the current group of young people. Decorative pattern needs to be innovatively combined with current popular culture, or use a few modern pattern design rules to increase, enlarge, or exaggerate former patterns. Under the influence of western culture, the simple style of modernism has become the current trend in various design fields. For example, mobile phone design gradually become simple; rather than pursue magnificent interior design, people pursue the effect that "less is superior to more, and simplicity is superior to complexity". It is not difficult to find embroidery that the traditional embroidery of Jincang involves various patterns, rich variety, full picture and gorgeous visual effects. Decorative patterns in modern bag design need to be highly refined and generalized to avoid over much complexity. Local application of Jincang Embroidery and empty processing in other places can bring the overall picture more sense of space.

\section{CONCLUSION}

Quanzhou Jincang Embroidery is not only a kind of traditional handicraft but also a kind of culture for the local people of Quanzhou. It is the spiritual support of the people. For example, local people must use the tablecloth embroidered with Jincang Embroidery to pray for happiness and health in the coming year in the unique and important festival in southern Fujian worship the god of heaven. Quanzhou is a rare region in China where many religions coexist and develop. There is rich and profound religious culture and the large and small temples that can be seen everywhere, fully reflecting the enthusiasm of Quanzhou people for worshipping Buddha. Therefore, they also attach great importance to religious items. The pattern decoration of religious items is mostly integrated into the local Jincang Embroidery technology. The special spiral double-gold embroidery technology can show patterns vividly, and create more gorgeous and delicate overall visual effect.

To continuously inherit and develop the traditional Chinese culture of Quanzhou Jincang Embroidery, it is necessary to combine with the new culture of the new era and integrate with the contemporary aesthetic and ideological standards. For example, we can make material innovation and technological innovation, boldly combine with hard materials, and 3D printing technology, and other modern new technology, innovate decoration patterns, simplify patterns, reduce overelaborate adornment, and constantly expand the application range of Jincang Embroidery. In addition, undoubtedly, to combine Quanzhou Jincang Embroidery with modern popular clothing and bags can attract more people to pay attention to the art of 
Quanzhou Jincang Embroidery, and promote its inheritance and development.

\section{References}

[1] Zheng Li. Quanzhou Jincang Embroidery Integrating Technology and Art. Art Panorama: 2015; 05: 97.

[2] Chen Xiaoping. Study on Regional Characteristics of Jincang Embroidery. Journal of Quanzhou Normal University: 2008; 36: 17-20.

[3] Yi Hongli. Embroidery Technology and Its Application in Costume Design. Movie Review: 2007; 08: 73-74.

[4] Li Zhenhao. Regeneration of Jincang embroidery traditional crafts. Art Panorama: 2017 (6) : 96-97.

[5] Zhou Yuexi. Chinese five-color aesthetics. Art: 2003: 124127.

[6] Li Huadong. The spirit and connotation of Minnan culture. Guangming Daily: 2009: 11-17. 